\title{
Inteligência competitiva no contexto das empresas mineiras de artefatos de
} estanho

\section{Paulo Henrique de Oliveira}

Wagner Sade

Doutor em Administração - UFMG. Mestrado em Engenharia de Produção - UFMG.Graduado em Administração - UFMG. Professor de Administração e Coordenador de Relações Empresariais - IFMG

Doutor em Engenharia de Materiais - REDEMAT Mestrado em Engenharia de Materiais - REDEMAT Graduado em Engenharia Metalúrgica - Instituto Militar de Engenharia - IME. Engenheiro de Segurança do Trabalho - Universidade Cândido Mendes - UCAM. Professor do Instituto Federal de Minas Gerais - IFMG (Engenharia Metalúrgica)

\section{http://dx.doi.org/10.1590/1981-5344/1885}

Investiga como as práticas da inteligência competitiva têm sido conduzidas pelas empresas mineiras de artefatos de estanho. Ao todo foram selecionadas 9 empresas, 0 que representou $90 \%$ da população das empresas de estanho operando na respectiva região. Os dados foram coletados por meio da aplicação de um questionário estruturado e analisados por meio das técnicas da estatística descritiva. Os resultados revelaram que a IC tem sido utilizada de maneira praticamente informal, especialmente nas empresas de menores portes analisadas. Observou-se, também, que os respectivos empresários compreendem que a IC é muito importante para o sucesso competitivos dos seus negócios, especialmente porque ajuda os seus gerentes a compreenderem melhor as necessidades dos seus clientes, na descoberta de novas oportunidades de negócios e no desenvolvimento de novos produtos, além do aumento da eficácia das estratégias competitivas utilizadas contra os seus concorrentes.

Palavras-chave: Inteligência competitiva; Empresas de estanho; Pesquisa descritiva. 


\section{Competitive intelligence in the context of enterprises artifacts of tin in Minas Gerais}

Investigates the practices of competitive intelligence (CI) has been conducted by companies artifacts tin of the Minas Gerais. Nine companies were selected, representing $90 \%$ of the population of firms operating in the respective region. Data were collected through the application of a structured questionnaire and analyzed using descriptive statistics techniques. The results showed that the CI has been practically used in informal manner, especially in the smaller sized companies analyzed. It was observed also that the respective entrepreneurs understand that the IC is very important to the success of your business competitive, especially because it helps your managers to better understand the needs of its customers in finding new business opportunities and development of new products, in addition to increasing the effectiveness of the competitive strategies used against their competitors.

Keywords: Competitive intelligence; Companies tin; Descriptive study.

Recebido em 11.10.2014 Aceito em 29.01.2016

\section{Introdução}

Competição é um fenômeno de destaque nos estudos conduzidos por muitos teóricos e pesquisadores dos campos da Microeconomia (CHAMBERLIN，1933; SCHUMPETER, 1934; MASON, 1939; BAIN, 1956; TIROLE, 1980; STIGLER, 1983) e da Administração Estratégica (ANSOFF, 1965; PORTER, 1980; CHANDLER, 1962, 1996; D'AVENI, 1995; BARNEY, 1996; CHEN; LIN; MICHEL, 2010). Compreender como determinadas empresas conseguem conquistar e sustentar vantagens competitivas por longos períodos de tempo em seus mercados consumidores ou indústrias tem sido um desafio constante para os respectivos estudiosos ao longo da história das empresas, mais precisamente, a partir da década de $30 \mathrm{com}$ os estudos de Ronald Coase sobre a natureza das firmas.

Mas foi a partir da década de 1980, período em que Michael Porter chamou a atenção para os fatores que determinam o grau da rivalidade existente entre as empresas que disputam a preferência dos mesmos consumidores dentro de um determinado mercado ou indústria, que muitos empresários e gestores estratégicos ao redor do mundo voltaram 
as suas atenções para o processo de monitoramento sistemático e contínuo dos movimentos realizados ou intencionados pelos concorrentes atuais e potenciais, apesar de estudos sobre monitoramento e incerteza ambientais já terem sido realizados em décadas anteriores por autores como Chandler (1962), Aguilar (1967) e Duncan (1971).

Recentemente, e com o objetivo de manter os altos executivos continuamente e instantaneamente bem informados sobre tudo o que está acontecendo nos ambientes internos e de negócios das suas empresas, verifica-se o surgimento e expansão de uma nova prática empresarial conhecida na literatura como inteligência competitiva (IC), o que pode ser comprovado pelo crescente número de empresas que tem estruturado unidades formais de IC para apoiar as suas estratégias competitivas, como é o caso de empresas como Xerox, Avnet, Procter \& Gamble, Motorola e IBM (PRESCOTT; MILLER, 2002).

No contexto acadêmico brasileiro, a IC tem emergido como um importante campo de pesquisa, haja vista o crescente número de estudos científicos apresentados em congressos e publicados em renomados periódicos nacionais nesses últimos anos, como é o caso da Perspectiva em Ciência da Informação, Ciência da Informação, Informação e Sociedade, Revista de Administração Contemporânea e Revista de Administração de Empresas. Algumas das principais universidades do Brasil, como as de Minas Gerais (UFMG), de Brasília (UnB), do Rio de Janeiro (UFRJ), de São Paulo (USP), do Rio Grande do Sul (UFRGS) e de Santa Catarina (UFSC) também têm promovido a IC a partir de seus programas de pós-graduação.

Buscando-se ampliar a base de conhecimento existente sobre o tema da IC, especialmente no contexto das empresas brasileiras de menores portes, o presente trabalho verifica como as empresas de estanho sediadas em São João del-Rei, importante cidade histórica do estado de Minas Gerais, monitoram os movimentos estratégicos realizados ou intencionados pelos seus concorrentes por meio de seus processos de IC.

Adicionalmente, também verifica a sua importância (IC) para o desenvolvimento de capacidades estratégicas relacionadas com 0 desenvolvimento e lançamento de novos produtos, alocação eficiente de recursos estratégicos, atendimento adequado das necessidades dos clientes, desenvolvimento de novos mercados, aumento da eficácia do processo estratégico, desenvolvimento de parcerias estratégicas com os fornecedores e de competências essenciais para um melhor posicionamento estratégico no mercado em que atuam.

Para o alcance dos objetivos delineados, o presente trabalho está organizado da seguinte forma: na primeira parte, que é representada por esta introdução, faz-se uma breve contextualização do tema da IC e apresentam-se os objetivos de pesquisa; em seguida, discute-se os aspectos centrais da IC; adiante, descreve-se os procedimentos metodológicos utilizados para o alcance dos objetivos delineados; por fim, analisa-se os dados, discute-se os resultados encontrados e apresenta-se as principais conclusões e limitações da pesquisa. 


\section{Análise da literatura}

\subsection{Competição e a necessidade de monitoramento ambiental}

Não se pode falar em eficácia estratégica, vantagem competitiva e desempenho superior sem antes compreender os significados da natureza e da dinâmica concorrencial existente nos setores industriais ou mercados consumidores onde as empresas estão inseridas. E o estudo do fenômeno da competição tem uma de suas origens históricas nos Estados Unidos, especialmente após a crise de 1929 quando economistas como Mason (1939) e Bain (1956) questionaram os limites da economia clássica de explicar as suas causas e propor soluções satisfatórias para os reflexos da respectiva crise sobre a economia norte-americana e, consequentemente, sobre o resto do mundo.

A partir do estudo das falhas do mercado, estas derivadas do poder conquistado por uma (monopólio) ou poucas empresas (oligopólios) de influenciar os preços praticados nos mesmos, os respectivos autores (Mason e Bain) observaram que o nível de preços e as quantidades ofertadas no respectivo mercado podiam ser controlados por um pequeno grupo de empresas. E este controle distorcia a livre concorrência (concorrência perfeita) e, consequentemente, a capacidade de escolha dos consumidores. Bain (1956) observou que as empresas monopolistas e oligopolistas construíam barreiras à entrada de novos concorrentes no mercado para manterem as suas posições vantajosas ou lucrativas. E dentre as principais barreiras apontadas pelo respectivo autor estão a proteção governamental, os ganhos de escala obtidos em decorrência de maior produtividade operacional, o acesso privilegiado aos canais de distribuição e a criação de patentes (BAIN, 1956).

No campo da estratégia, por exemplo, Porter (1981) utilizou os estudos de Mason (1939) e Bain (1956) na forma de um modelo conhecido na literatura de negócios como Estrutura-Conduta-Desempenho (Structure-Conduct-Performance, SCP, no inglês). Esse modelo, apoiado nos fundamentos básicos da Economia Industrial, defende que a estrutura da indústria determina a conduta utilizada pelas empresas (estratégia) para o alcance de desempenhos superiores ou acima da média. Observase, entretanto, que as ações implementadas pelas empresas dentro de uma determinada indústria afetam o comportamento e o lucro das demais no longo prazo (BAIN, 1956; PORTER, 1981).

Contrapondo-se a perspectiva estática do mercado defendida pelos economistas clássicos ou mais ortodoxos, os representantes da Escola Austríaca (SCHUMPETER, 1934; HAYEK, 1945) chamaram a atenção para a dinâmica dos mercados e da competição, uma vez que os empresários, na busca por lucros extraordinários, se enveredavam em campos muitas vezes desconhecidos e caracterizados por altas taxas de riscos. Como consequência, a inovação de processos, produtos e serviços era incentivada pelos respectivos empresários na tentativa de se 
diferenciarem dos seus concorrentes e, com isso, suprir os desejos e as necessidades dos consumidores em constante transformação. Assim, para ter sucesso nesses mercados dinâmicos e imprevisíveis, as empresas deveriam ser capazes de se reinventarem continuamente, o que Schumpeter (1934) chamou de "destruição criativa". E essas são as condições essenciais que exemplificam o que os economistas chamam de "competição schumpeteriana".

Quando se discute os assuntos da competição e da estratégia, um processo que precisa ser eficazmente conduzido pelas empresas é o de monitoramento ambiental. $E$ os principais estudos realizados sobre 0 mesmo foram conduzidos por autores como Dill (1958), Aguilar (1967), Duncan (1971), Child (1972), Porter (1980), Hambrick (1981, 1982) e Choo (1999). Para os respectivos autores, os decisores da alta cúpula empresarial precisam estar continuamente bem informados sobre tudo o que está acontecendo em seus ambientes de negócios, uma vez que surpresas desagradáveis podem colocar em risco a sobrevivência e o crescimento das suas respectivas empresas nos mercados em que atuam ao longo do tempo.

\subsection{Inteligência competitiva: potencializando o processo estratégico}

Inteligência Competitiva (IC) tem sido compreendida na literatura da Estratégia Empresarial e demais áreas correlatas (ex. Marketing e Gestão Estratégica da Informação) como uma importante ferramenta de suporte à tomada de decisão estratégica. Normalmente definida como um processo composto pelas etapas de planejamento, coleta, análise e disseminação de produtos de inteligência acionáveis para os decisores alocados na alta cúpula empresarial (FULD, 1995; KAHANER, 1996; TYSON, 1998; BERNHARDT, 2003; MCDONALLE; VELLA, 2004; QIU, 2008), a IC tem ajudado muitas empresas a melhor compreenderem a dinâmica e a complexidade dos seus ambientes competitivos, reduzindo incertezas e, consequentemente, os riscos de falhas das estratégias competitivas delineadas para o alcance dos objetivos de longo prazo propostos.

Quando se discute a origem da IC, autores como Prescott (1999) e Miller (2002), por exemplo, têm apontado três momentos específicos da história da humanidade e das empresas: (a) os ensinamentos do filósofo chinês Sun Tzu sobre a Arte da Guerra há milhares de anos atrás (contexto militar); (b) as políticas de segurança nacional utilizadas por muitos países durante a Segunda Guerra Mundial e Guerra Fria (contexto governamental) e (c) os estudos realizados por Michael Porter no início da década de 80 sobre a estrutura da indústria e a análise dos competidores (contexto empresarial). Especificamente em relação a este último, Porter (1980) chamou a atenção dos gestores para a necessidade de um acompanhamento sistemático e contínuo das ações e intenções dos concorrentes estratégicos com o objetivo de antecipar e neutralizar as 
possíveis ameaças que pudessem colocar em risco a sobrevivência e o crescimento empresariais em seus respectivos mercados consumidores.

Para muitos autores, a IC começa com o planejamento das suas atividades, ou seja, com a identificação das necessidades de inteligência da empresa e dos seus respectivos usuários (MILLER, 2002; BERNHARDT, 2003; LIEBOWITZ, 2006). Nesta etapa do processo de geração da IC pode-se utilizar uma técnica conhecida como $5 \mathrm{~W} 1 \mathrm{H}$ (What, Who, Where, When, Why e How). Assim, identifica-se quais são as necessidades de inteligência da empresa e quem são os responsáveis pelas decisões estratégicas, onde os respectivos produtos de inteligência serão gerados e em que momento (quando) os mesmos deverão ser disponibilizados para os respectivos decisores estratégicos, as razões (por que) que levaram ao surgimento das necessidades de inteligência e como as respectivas inteligências serão operacionalizadas pelos usuários das mesmas, ou seja: pelos decisores estratégicos.

Identificadas as necessidades de inteligência e os seus respectivos usuários, a próxima etapa do processo de IC volta-se para a coleta dos dados e das informações sobre os concorrentes e demais eventos de interesse que possam influenciar o comportamento e o desempenho das empresas no longo prazo. Nesta etapa os profissionais responsáveis pela mesma selecionam as fontes de informações mais adequadas e monitoram os movimentos estratégicos realizados ou intencionados pelos concorrentes e as tendências do macroambiente, especialmente das mudanças que estão ocorrendo nos fatores econômicos, sociais/demográficos, político, tecnológicos e ambientais (FULD, 1995; KAHANER, 1996; PRESCOTT e MILLER, 2002; HERRING, 2002; MILLER, 2002; BARBOSA, 2006; OLIVEIRA; ALMEIDA; LACERDA, 2007).

Destaca-se, ainda, que esses recursos informacionais devem ser obtidos, de maneira ética e legal (fontes públicas), tanto de fontes primárias quanto secundárias, internas e/ou externas às empresas. A legalidade é uma parte fundamental das atividades de inteligência desenvolvidas pelas empresas, pois a mesma não é e nem pode ser confundida com a prática de espionagem, uma vez que a mesma é uma prática ilegal e deve ser combatida por todas as empresas que utilizam a IC para a potencialização dos seus processos estratégicos (MILLER, 2002; BERNHARDT, 2003; ABRAIC, 2012; SCIP, 2012).

De posse dos dados e das informações necessárias sobre os atores e eventos relevantes do ambiente competitivo, os profissionais da inteligência direcionam os seus esforços intelectuais para a transformação dos mesmos em produtos de inteligência acionáveis para os gestores estratégicos, ou seja, recomendações, insights, alertas antecipados ou relatórios contendo informações analisadas e com alto valor agregado para a tomada de decisão estratégica. E nesta etapa do processo da IC alguns métodos e técnicas podem ser utilizados pelos profissionais da inteligência, como são os casos da análise SWOT (Strenghts, Weaknesses, Opportunities, Threats), modelo das Cinco Forças de Porter (Poder de Barganha dos Compradores, Poder de Barganha dos Fornecedores, Ameaças de Novos Entrantes, Ameaças de Produtos Substitutos, 
Rivalidade existente entre os Competidores Atuais); Análise de Cenários, Jogos de Guerra, Matriz BCG (Boston Consulting Group), Fatores Críticos de Sucesso, dentre outros (MILLER, 2002; TARAPANOFF, 2001).

Finalmente, na última etapa do processo da IC, os produtos de inteligência são disseminados para os seus usuários. Esta atividade pode acontecer de diversas maneiras, desde que atenda às preferências e as necessidades dos mesmos. Assim, as inteligências geradas podem ser enviadas por e-mail, compartilhadas em reuniões periódicas, disponibilizadas em relatórios e demais documentos empresariais. Nessa etapa dois pontos críticos devem ser cuidadosamente observados pelos profissionais da IC, quais sejam: o momento em que os produtos de inteligência deverão ser entregues para os decisores estratégicos e o formato adequado, conforme a solicitação dos mesmos (WEST, 2001; MILLER, 2002; BERGERON; HILLER, 2002).

\subsection{A indústria de estanho no Brasil}

O estanho é um dos metais mais antigos conhecidos pelo homem. Ele foi descoberto pelos egípcios há 3500 a.C. que fabricavam os utensílios de mesa, cozinha, castiçais, bandejas e estatuetas (MARGUEL LTDA, 2012). Estudos arqueológicos realizados no domínio interfluvial dos rios Tigre e Eufrates, antiga Mesopotâmia, hoje Iraque, revelaram que o uso do bronze, a liga de estanho e cobre, remonta a 3200 a.C. Reconhece-se, portanto, que o estanho foi um dos primeiros metais trabalhado pelo homem e na forma de bronze era utilizado para manufatura de armas e ferramentas. Este fato caracterizou-se em um marco da evolução tecnológica das civilizações, a denominada Idade do Bronze.

A História admite que por volta do ano 2500 a.C. tenha ocorrido escassez de estanho em determinadas regiões orientais, o que estimulou o desenvolvimento das rotas comerciais tradicionais, rumo às reservas estaníferas da Espanha e "Cassiterides" ou "Ilhas de Estanho", mencionadas pelo historiador Heródoto. Supõe-se que esta última se referia às formações geológicas de Cornwall (Inglaterra), possivelmente uma importante fonte de estanho entre 500 a 100 a.C.

A utilização do estanho pelos povos antigos, provavelmente, deveuse às peculiaridades físicas e químicas do metal, tais como: baixo ponto de fusão $\left(231,9^{\circ}\right)$, afinidade em formar ligas de cobre e chumbo, alta resistência à corrosão e à oxidação, o fato de não ser tóxico e de se ter boa aparência externa; lustroso e prateado. Dentre as aplicações destacam-se os revestimentos de estanho em chapas de aço, as folhas de flandres utilizadas como embalagens. O estanho puro é macio e apresenta baixa trabalhabilidade. Usualmente, utiliza-se uma liga conhecida como "pewter", que contém 93,5\% de estanho, $1,5 \%$ de cobre e $5 \%$ de antimônio. O cobre aumenta a resistência mecânica e o antimônio aumenta a dureza do estanho (FAEMAM ESTANHOS, 2012).

É interessante ressaltar que até o Século XIX, Cornwall era responsável por um terço da produção mundial de estanho, porém, 
atualmente suas reservas estão esgotadas. Uma Carta Régia, datada de 28 de fevereiro de 1765, conferindo a Domingos Ferreira o direito de pesquisar cassiterita, o minério de estanho, na Comarca de São Paulo, foi a primeira referência histórica sobre a descoberta de estanho no Brasil. Admite-se, entretanto, que o início das atividades extrativistas deste minério no país remonta a 1903, caracterizando-se por atividades essencialmente garimpeiras e restringindo-se à exploração rudimentar das aluviões estaníferas do rio Camaquã, no município de Encruzilhada do Sul (RS).

No contexto brasileiro verifica-se que a indústria de estanho apresentou forte crescimento nas décadas de 70 e 80, especialmente no mercado internacional. Segundo Rodrigues (2009, p.236), o estanho "é uma das commodities minerais que teve na história recente da economia mineral brasileira o privilégio de experimentar dois ciclos de boom de preços no mercado internacional: o primeiro no período de 1975-1985 e o segundo iniciado a partir de 2004". Ainda segundo este relatório, esses resultados positivos projetou o Brasil como um player global no mercado internacional de não-ferrosos ao ser o maior exportador líquido de Snmetálico, especialmente no final da década de 80.

E essa posição de liderança, conforme opinião de alguns especialistas no respectivo mineral decorreu da conjunção de três fatores principais: (a) a estratégia de conhecimento da Geodiversidade da Amazônia como elemento precursor de alavancagem de mudanças definidas pelos programas de levantamentos geológicos básicos e projetos de pesquisas mineral específicos (RADAM, 1970-1985; Província Estanífera de Rondônia, 1967-1978; Sulfetos do Uatumã, 1976-1978); (b) a política de sustentação artificial de preços no mercado internacional de estanho, o que favoreceu a atração de novos investimentos em pesquisa mineral e em infraestrutura do parque minero-estanífero nacional, durante as décadas de 70 e 80; e (c) as vantagens comparativas inatas às jazidas/minas de classe internacional do Pitingá (AM) e Bom Futuro (RO) (RODRIGUES, 2009).

Precisamente em relação ao ambiente competitivo, indícios têm apontado para um contexto de severo acirramento da competição, especialmente entre os países produtores emergentes, como são os casos da China, Indonésia e o Peru. Estes países são alguns dos principais detentores de reservas do respectivo mineral, mantendo uma hegemonia no setor com aproximadamente $70,2 \%$ do mercado estanífero internacional.

Em São João del-Rei a produção de peças decorativas e artesanatos iniciou-se em 1968 pelo artesão inglês John Somers. Posteriormente, novas fábricas como a Marguel, Faemam e outras foram inauguradas na região. Enfim, as jazidas de classe internacional, do Pitinga, no Amazonas e Bom Futuro, em Rondônia, só vieram a ser descobertas na década de 80, projetando o Brasil como maior produtor de 1988 a 1990, consolidando o país como importante exportador de estanho metálico para o mercado internacional (RODRIGUES, 2009). 


\section{Metodologia}

Conforme mencionado anteriormente, verifica-se que a inteligência competitiva (IC) tem ganhado em importância para os gestores contemporâneos, especialmente para àqueles responsáveis pelas tomadas de decisões estratégicas de empresas instaladas em ambientes competitivos caracterizados como complexos e dinâmicos, também chamado por D'Aveni (1995) de hipercompetitivos. Nesses tipos de ambientes, onde as vantagens competitivas tendem a ser rapidamente imitadas ou superadas pelos concorrentes (D'AVENI; DAGNINO; SMITH, 2010; SIRMON et al. 2010), a necessidade por informações valiosas e instantâneas sobre os movimentos e as intenções dos concorrentes podem ser determinantes para a sobrevivência e crescimento das respectivas empresas nos mercados em que atuam ao longo do tempo.

Por ser uma prática em expansão no mundo dos negócios, a IC tem chamado a atenção de muitos pesquisadores interessados em fenômenos como competição, estratégia e vantagem competitiva, especialmente no contexto das empresas de menores portes, como é o caso das empresas de artefatos de estanho instaladas em São João del-Rei. Assim, para verificar como as respectivas empresas monitoram os seus ambientes competitivos, e percebem a importância da inteligência competitiva para o sucesso competitivo das mesmas, foi conduzido uma pesquisa de natureza qualitativa e descritiva com $90 \%$ das empresas de estanho instaladas na respectiva cidade histórica de Minas Gerais. Ao todo foram selecionadas 9 empresas com base na importância das mesmas para a região e na disponibilidade das mesmas de participarem da pesquisa. Os perfis das respectivas empresas estão detalhados na Tabela 1 a seguir.

Tabela 1 - Perfil das empresas analisadas

\begin{tabular}{cccc}
\hline Empresas & $\mathbf{N}^{\mathbf{0}}$. Funcionários & $\begin{array}{c}\text { Taxa de Crescimento Médio } \\
\text { (Últimos } \mathbf{5} \text { anos) }\end{array}$ & $\begin{array}{c}\text { Experiência em } \\
\text { Monitoramento dos } \\
\text { Concorrentes }\end{array}$ \\
\hline $\mathrm{A}$ & 4 & $15,0 \%$ & 8 anos \\
$\mathrm{B}$ & 30 & $10,0 \%$ & 5 anos \\
$\mathrm{C}$ & 4 & $5,0 \%$ & 3 anos \\
$\mathrm{D}$ & 5 & $5,0 \%$ & 2 anos \\
$\mathrm{E}$ & 10 & $5,0 \%$ & 4 anos \\
$\mathrm{F}$ & 10 & $20,0 \%$ & 0 anos \\
$\mathrm{G}$ & 5 & $10,0 \%$ & 0 anos \\
$\mathrm{H}$ & 10 & $0,0 \%$ & 5 anos \\
$\mathrm{I}$ & 3 & $0,0 \%$ & 0 anos \\
\hline Média & $\mathbf{9}$ & $\mathbf{7 , 8 \%}$ & $\mathbf{3 , 0}$ anos \\
Mínimo & $\mathbf{3}$ & $\mathbf{0 , 0 \%}$ & $\mathbf{0 , 0}$ anos \\
Máximo & $\mathbf{3 0}$ & $\mathbf{2 0 , 0 \%}$ & $\mathbf{8 , 0}$ anos \\
\hline
\end{tabular}

Fonte: Dados da pesquisa ( $n=9$ observações).

Nota: As empresas estão identificadas pelas letras A, B, C, ... I por motivo de anonimato, pois os respondentes solicitaram que os nomes das suas respectivas empresas não fossem mencionados na presente pesquisa. 
Para a coleta de dados foi desenvolvido um questionário estruturado contendo questões fechadas com opções de respostas excludentes. Os dados foram coletados pessoalmente por um dos pesquisadores no mês de março de 2012. A duração de cada entrevista ficou em torno de 40 minutos, e as principais dúvidas acerca das terminologias utilizadas no mesmo foram prontamente respondidas pelo responsável pela aplicação dos respectivos questionários. Para a validação do mesmo foi realizado um pré-teste com dois gestores estratégicos duas semanas antes da realização da pesquisa propriamente dita (empresas A e D).

Finalmente, técnicas da estatística descritiva foram utilizadas para a análise dos dados coletados na pesquisa de campo, especialmente de tendência central como a média e o desvio-padrão, além da frequência de resposta às perguntas do questionário que abordaram variáveis como intensidade competitiva, frequência de monitoramento dos concorrentes, existência de estrutura formal (departamentos) para a consecução das atividades de acompanhamento dos movimentos e intenções dos concorrentes, a quantidade de profissionais diretamente envolvidos com as respectivas atividades e importância da IC para o desenvolvimento de capacidades estratégicas. A escolha dessas variáveis levou em consideração os estudos realizados por renomados pesquisadores de IC no Brasil e no resto do mundo.

\section{Apresentação e análise dos resultados}

\subsection{Competição e estrutura para o monitoramento dos concorrentes}

Quando se analisa o comportamento informacional dos gestores estratégicos, em termos de monitoramento do ambiente competitivo, um aspecto que tem sido considerado pelos pesquisadores interessados no fenômeno da competição é o nível da intensidade derivada das ações e reações competitivas implementadas pelas empresas instaladas dentro de um determinado mercado quando as mesmas disputam as preferências dos mesmos clientes.

Autores como Porter (1980), D 'Aveni (1995), Ang (2008), Pachecode-Almeida (2010), Chen, Lin e Michel (2010), Sirmon et al. (2010) e D'Aveni, Dagnino e Smith (2010), por exemplo, têm associado a intensidade competitiva com o grau da rivalidade existente entre os competidores que atuam dentro de uma determinada indústria. E a medida desta rivalidade tem sido determinada pelo número e tamanho dos respectivos competidores, pelos movimentos e contra-movimentos estratégicos realizados pelos mesmos dentro de um determinado período de tempo e pela taxa de crescimento ou expansão dos mercados consumidores, dentre outros (PORTER, 1980).

A suposição defendida por muitos estudiosos é a de que o respectivo comportamento informacional (frequência de monitoramento ambiental) tende a ser influenciado positivamente pelo nível da intensidade da competição existente no mercado, uma vez que o grande volume de ações 
e reações competitivas implementadas pelas empresas concorrentes normalmente proporciona maiores níveis de incertezas e, consequentemente, maiores necessidades dos decisores estratégicos por informações atualizadas e instantâneas sobre a ocorrência de eventos externos que possam ter alguma influência sobre o comportamento e desempenho de suas empresas ao longo do tempo (DUNCAN, 1971; WEST, 2001; BERNHARDT, 2003; LIEBOWITZ, 2006).

Trazendo-se essa discussão para o contexto das empresas de artefatos de estanho instaladas em São João del-Rei, observou-se que para a grande maioria dos gestores entrevistados (56\%) o nível da competição existente no mercado pode ser considerado como de moderada a baixa intensidade, conforme a percepção dos mesmos. Este fato é corroborado pela baixa frequência com que os mesmos monitoram os seus concorrentes (67\%) (Figuras 1 e 2). Como consequência, a suposição de que existe uma associação positiva entre a intensidade da competição percebida pelos decisores estratégicos e a frequência com que as suas empresas monitoram os concorrentes parece ser verdadeira neste tipo de indústria. Contudo, este indício poderá ser melhor explorado por futuras pesquisas que analisem as respectivas variáveis em amostras maiores, diversificadas e estatisticamente significativas.

Já em relação à formalização do processo de monitoramento dos concorrentes, constatou-se que a grande maioria das empresas não tem um departamento estruturado para a condução da respectiva atividade $(67 \%)$, o que pode ser em decorrência da grande parte das empresas pesquisadas serem de micro porte. Entretanto, apesar da inexistência da respectiva estrutura formal, constatou-se que para $55 \%$ dos entrevistados, as suas respectivas empresas possuem pelo menos três profissionais diretamente envolvidos com o respectivo processo, apenas uma tem um único funcionário e três não possuem nenhum funcionário responsável pelo acompanhamento dos movimentos dos concorrentes, o que está em sintonia com os dados do gráfico da Figura 2 que demonstra a baixa frequência de monitoramento ambiental.

A informação extraída da análise desses dados permite supor que existe uma possível relação entre o porte da empresa e a quantidade de funcionários diretamente alocados no monitoramento dos concorrentes. $E$ como consequência, acredita-se que as empresas de médio e grande portes tendem a conduzir os seus processos de monitoramento dos concorrentes em estruturas mais formais, departamentalizadas e com maior número de profissionais especializados, uma vez que as mesmas normalmente dispõem de maiores quantidades de recursos financeiros, tecnológicos e humanos. Importante destacar que essa conclusão não significa que o acompanhamento dos concorrentes não possa ser efetivamente realizado pelas empresas de menores portes, pelo contrário, nem sempre a consecução eficiente e eficaz do respectivo processo demanda grandes estruturas formalizadas e muitas pessoas envolvidas com o respectivo processo (WEST, 2001; MILLER, 2002; BERNHARDT, 2003; LIEBOWITZ, 2006). 
Finalmente, em relação aos dados obtidos da variável "compartilhamento das informações sobre os concorrentes entre os funcionários" observou-se que a metade das empresas pesquisadas incentivam a troca frequente de informações entre os seus funcionários, especialmente nas empresas de maiores portes (pequeno e médio). Essa informação pode ser decorrente do fato de que as empresas maiores normalmente possuem mais funcionários do que as demais, além de normalmente enfrentarem concorrências mais acirradas em decorrência da sua atuação em múltiplos mercados consumidores. Assim, uma suposição final que se pode inferir é a de que o compartilhamento de informações entre os funcionários pode estar associado com a intensidade da competição existente no setor e com o porte das empresas, este representado pelo número de funcionários das mesmas

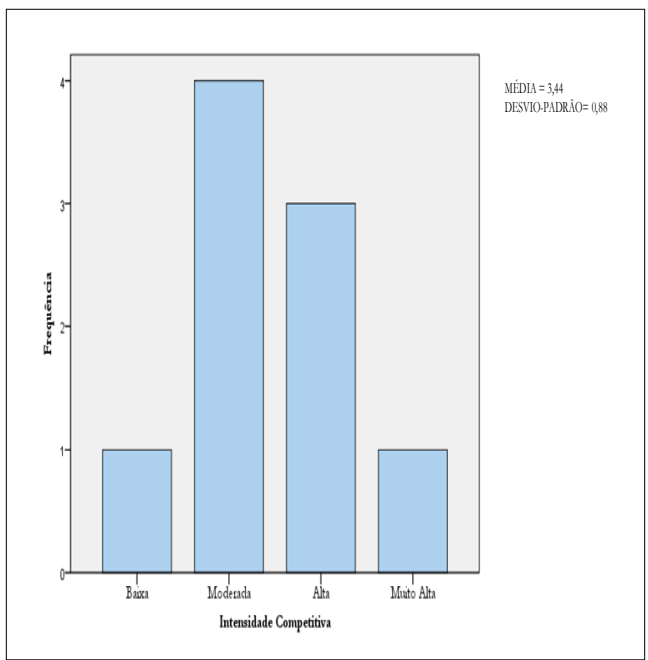

FIGURA 1: Intensidade da competição percebida pelos gestores Fonte:dados da pesquisa

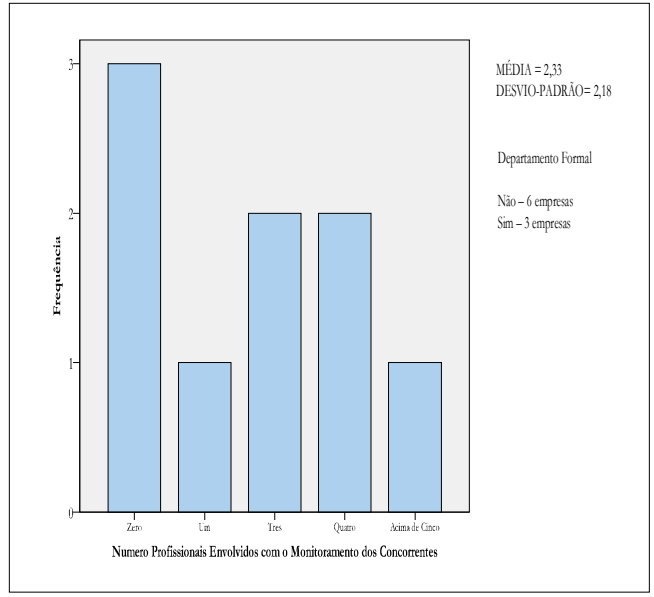

FIGURA 3: Quantidade de profissionais envolvidos diretamente com o monitoramento dos concorrentes

Fonte:dados

da pesquisa

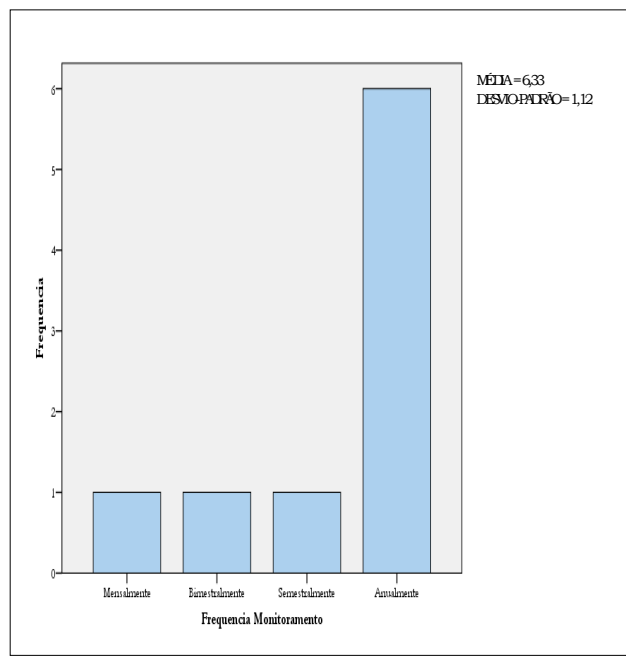

FIGURA 2: Frequência de monitoramento dos concorrentes

Fonte:dados da pesquisa

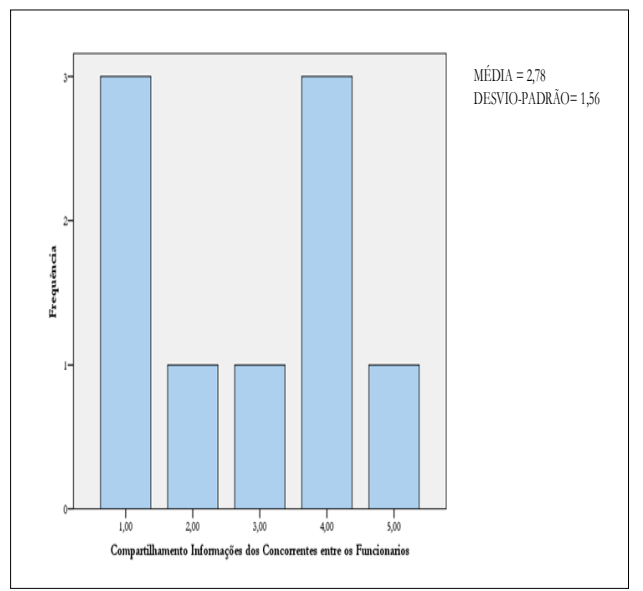

FIGURA 4: Compartilhamento das informações concorrenciais entre os funcionários

Fonte:dados da pesquisa 


\subsection{Importância da inteligência competitiva para o desenvolvimento de capacidades estratégicas}

Em muitas situações os resultados do monitoramento dos concorrentes, uma das principais etapas do processo de inteligência competitiva, condicionam os gestores alocados na alta cúpula empresarial a uma melhor tomada de decisão estratégica. Este fato interfere, consequentemente, no desenvolvimento das condições internas necessárias para que as empresas enfrentem as ameaças competitivas de maneira mais rápida e eficaz, além de ajudar os seus decisores estratégicos a implementarem estratégias competitivas que permitam às suas respectivas empresas a conquista e a sustentação de vantagens competitivas por longos períodos de tempo em seus respectivos mercados ou indústrias (TYSON 1998; MILLER, 2002; BERNHARDT, 2003).

$\mathrm{E}$ nos mercados considerados como altamente competitivos, fatores como a criação contínua de novos produtos, alocação eficiente de recursos, conquista de novos mercados, desenvolvimento de competências essenciais, atendimento das necessidades dos clientes atuais, relacionamentos estratégicos com os fornecedores, eficácia das estratégias competitivas formuladas e o lançamento rápido de produtos inovadores podem ser determinantes para o sucesso competitivo das empresas em decorrência de um melhor posicionamento estratégico (PORTER, 1980; D'AVENI, 1995; ANG, 2008; CHEN; LIN; MICHEL, 2010; SIRMON et al., 2010). A Tabela 2 resume os dados referentes à importância da inteligência competitiva para a consecução dos respectivos fatores no contexto das empresas de estanho analisadas.

Tabela 2 - Estatística sobre a importância da IC para as empresas de artefatos de estanho

\begin{tabular}{lcccc}
\hline \multicolumn{1}{c}{ Importância da IC para } & Média & Desvio-Padrão & Mín & Máx \\
\hline Desenvolvimento de Novos Produtos & 3,44 & 0,52 & 3 & 4 \\
Alocação Eficiente de Recursos & 3,33 & 0,70 & 2 & 4 \\
Conquista de Novos Mercados & 3,67 & 0,50 & 3 & 4 \\
Desenvolvimento de Competências Essenciais & 2,67 & 1,00 & 1 & 4 \\
Atendimento das Necessidades dos Clientes & 3,78 & 0,44 & 3 & 4 \\
Relacionamentos Estratégicos com Fornecedores & 3,22 & 0,44 & 3 & 4 \\
Lançamento Rápido de Produtos Inovadores & 3,11 & 0,78 & 2 & 4 \\
Eficácia das Estratégias Competitivas & 3,33 & 0,50 & 3 & 4 \\
\hline
\end{tabular}

Fonte: Dados da pesquisa $(n=9)$

Nota: Escala de mensuração (1- Nenhuma Importância, 2 - Baixa Importância, 3 - Média Importância, 4 - Alta Importância)

A partir da análise dos dados expostos na Tabela 2 verificou-se que o processo de inteligência competitiva utilizado pelas empresas de artefatos de estanho no monitoramento dos concorrentes e apoio ao processo estratégico tem papel fundamental nos diversos aspectos estratégicos considerados pelos autores contemporâneos para a sobrevivência e o crescimento das mesmas. E dentre as capacidades estratégicas consideradas observou-se que a inteligência competitiva tem 
maior importância para o desenvolvimento de ações que levem a um melhor atendimento das necessidades dos clientes (Média $=3,78$ ), seguida de perto pela conquista de novos mercados (Média $=3,67$ ). Esses resultados podem estar positivamente associados ao fato dos produtos de estanho terem alto valor agregado e de serem mais bem aceito nos mercados internacionais. Importante destacar que durante a coleta de dados constatou-se que a grande parte dos entrevistados tem como preferência a venda dos seus produtos para os respectivos tipos de mercados.

Em relação às demais variáveis, a grande parte dos entrevistados respondeu que os esforços de inteligência desenvolvidos por suas empresas são muito importantes para que as mesmas desenvolvam as condições necessárias para um melhor posicionamento competitivo em seus mercados consumidores. A única exceção foi em relação ao desenvolvimento de competências essenciais (Média $=2,67$ ). Esse resultado discrepante pode estar associado aos seguintes fatores: (a) ao que os entrevistados entenderam por competências essenciais, uma vez que a pergunta foi feita de maneira genérica e (b) à grande parte das empresas ser de micro porte e possivelmente não estarem familiarizadas com o respectivo conceito, uma vez que o mesmo foi proposto por Prahalad e Hamel (1990) especialmente para o contexto das grandes empresas globais. E como durante as entrevistas não ficaram evidentes o possível desconhecimento dos entrevistados em relação ao respectivo conceito, a respectiva variável foi considerada nesta análise.

\section{Considerações finais}

Nesses últimos anos, a IC tem se consolidado como uma importante atividade de suporte à tomada de decisão estratégica, especialmente porque a mesma tem como principal meta a de manter os decisores estratégicos continuamente e instantaneamente bem informados sobre tudo de relevante que esteja acontecendo em seus ambientes competitivos e que possam ter algum impacto sobre o comportamento e desempenho das suas respectivas empresas nos mercados em que atuam ao longo do tempo (FULD, 1995; LIEBOWITZ, 2006).

E como uma atividade voltada para 0 monitoramento dos concorrentes e demais eventos de interesse do ambiente de negócios, a IC tem despertado o interesse de muitos pesquisadores ao redor do mundo nesses últimos anos, especialmente a partir da década de 80 quando Michael Porter chamou a atenção dos gestores para a necessidade de um acompanhamento contínuo e sistemático do ambiente de negócios na tentativa de antecipar e neutralizar as possíveis ameaças ambientais, como também, possibilitar a descoberta de oportunidades de negócios mais vantajosas para as suas respectivas empresas.

No contexto acadêmico verifica-se que a grande parte das pesquisas realizadas sobre o respectivo tema tem se concentrado principalmente nas empresas de grande porte, talvez em decorrência das mesmas terem maiores condições financeiras e estruturais para a consecução das suas 
respectivas atividades de inteligência. E essa "preferência" dos pesquisadores tem aberto novas possibilidades de pesquisas, especialmente nas empresas de menores portes, como foi o caso dessa pesquisa ao analisar como as micro, pequena e média empresas da indústria de estanho sediadas na cidade histórica de São João del-Rei percebem a competição em seus ambientes de negócios e monitoram os seus concorrentes para uma melhor tomada de decisão estratégica e o desenvolvimento de capacidades diferenciadas que permitam as mesmas maior lucratividade.

Assim, com base nos dados analisados encontrou-se indícios de que a intensidade da competição existente no mercado, conforme a percepção dos respectivos entrevistados, esteja positivamente associada com a frequência com que os movimentos estratégicos realizados ou intencionados pelos concorrentes são monitorados. Isso parece óbvio, uma vez que em ambientes competitivos caracterizados por uma intensa competição a necessidade dos gestores por informações de qualidade e atualizada tende a ser maior, e vice-versa. Essa afirmação está em sintonia com as ideias de autores como D'Aveni (1995), Ang (2008), Chen, Lin e Michel (2010); D'Aveni, Dagnino e Smith (2010) e Sirmon et al. (2010).

Outro indício importante encontrado é a de que a formalização do processo de IC e a sua condução por unidades funcionais especializadas podem estar associadas ao porte das empresas. Nessa pesquisa observouse que apenas as empresas de médio porte tinham departamentos responsáveis pelas atividades de inteligência. Constatou-se, também, que a quantidade de funcionários diretamente envolvidos com 0 monitoramento dos concorrentes também parece estar associada ao tamanho das empresas analisadas, uma vez que as empresas maiores em tamanho normalmente possuem mais profissionais envolvidos com 0 monitoramento e a produção da IC demandada por seus decisores estratégicos (MILLER, 2002; BERNHARDT, 2003).

Por último, a conclusão a que se chega nesta pesquisa em relação à importância da IC para as empresas pesquisadas é a de que a mesma tem papel fundamental para o desenvolvimento dos fatores que são estratégicos para a sobrevivência e o crescimento das respectivas empresas, especialmente porque ajuda no desenvolvimento e lançamento rápido de novos produtos nos mercados, aumenta a eficácia das estratégias competitivas formuladas, permite um melhor atendimento das necessidades dos clientes, facilita a descoberta e a exploração de novos mercados e, finalmente, favorece uma melhor alocação dos recursos empresariais e, consequentemente, a conquista de retornos financeiros positivos. Essas conclusões estão de acordo com os estudos realizados por autores como Fuld (1995), Kahaner (1996), Tyson (1998), West (2001), Miller (2002), Herring (2002), Bernhardt (2003), Liebowitz (2006), dentre outros.

Apesar deste estudo ter sido conduzido com quase todas as empresas de estanho instaladas na cidade de São João del-Rei e região, os resultados encontrados não podem ser generalizados para as demais 
empresas de estanho que operam no país ou no exterior. Outra importante limitação deriva do fato de que a análise da importância da IC para as empresas pesquisadas levou em consideração apenas a percepção dos entrevistados, o que poderá ser melhor explorado por futuras pesquisas interessadas no respectivo tema a partir da utilização de metodologias e técnicas mais avançadas de coleta e análise de dados.

\section{Referências}

ASSOCIAÇÃO BRASILEIRA DOS ANALISTAS DE INTELIGÊNCIA COMPETITIVA - ABRAIC. [Site oficial]. Disponível em: <http://www.abraic.org.br>. Acesso em: 20 mar. 12.

AGUILAR, F. J. Scanning the business environment. New York, NY: Macmillan Co, 1967.

ANG, S. H. Competitive intensity and collaboration: impact on firm growth across technological environments. Strategic Management Journal, v. 29, p. 1057-1075, 2008.

ANSOFF, I. Corporate strategy. New York: McGraw Hill, 1965.

BAIN, J. S. Barriers to new competition. Cambridge, MA: Harvard University Press, 1956.

BARBOSA, R. R. Uso de fontes de informação para inteligência competitiva: um estudo da influência do porte das empresas sobre o comportamento informacional. Encontros Bibli (UFSC), n. esp, p. 91-102, $2006 . \quad$ Disponível em: $<$ https://periodicos.ufsc.br/index.php/eb/article/viewFile/15182924.2006v11nesp1p91/388 >. Acesso em: 16 mar. 2016.

BARNEY, J. B. Types of competition and the theory of strategy: toward an integrative framework. Academy of Management Review, v. 11, n. 4, p. 791-800, 1986.

BERGERON, P.; HILLER, C. A. Competitive intelligence. Annual Review of Information Science and Technology, v. 36, p. 353-390, 2002.

BERNHARDT, D. Competitive intelligence: how to acquire and use corporate intelligence and counter-intelligence. London: Prentice Hall, 2003.

CHAMBERLIN, E. H. The theory of monopolistic competitition. Cambridge, MA: Harvard University Press, 1933.

CHANDLER, A. Strategy and structure. Cambridge, MA: MIT Press, 1962.

CHANDLER, A. Competitor analysis and interfirm rivalry: toward a theoretical integration. Academy of Management Review, v. 21, p. 100134, 1996.

CHEN, M. J.; LIN, H.C.; MICHEL, J. G. Navigating in a hypercompetitive environment: the roles of action aggressiveness and TMT integration. Strategic Management Journal, v. 31, p. 1410-1430, 2010. 
CHILD, J. Organizational structure, environment and performance: the role of strategic choice. Sociology, v. 5, p. 01-22, 1972.

$\mathrm{CHOO}, \mathrm{C}$. W. The art of scanning the environment. Bulletin of the American Society for Information Science, v. 3, n. 25, p.13-19, 1999.

D'AVENI, R. A. Hipercompetição: estratégias para dominar a dinâmica de mercado. Rio de Janeiro: Campus, 1995.

D'AVENI, R. A.; DAGNINO, G. B.; SMITH, K. G. The Age of Temporary Advantage. Strategic Management Journal, v. 31, n. 13, p. 1371-1385, 2010.

DILL, W. R. Environment as an influence on managerial autonomy. Administrative Science Quarterly, v. 2, n. 4, p. 409-443, Mar. 1958.

DUNCAN, R. B. Characteristics of organizational environments and perceived environmental uncertainty. Administrative Science Quarterly, v. 17 , n. 3, p. 313-327, 1972.

FAEMAM ESTANHOS. Catálogo de vendas. São João del-Rei, 2012.

FULD, L. The new competitor intelligence. New York: Wiley, 1995.

HAYEK, F. A. The use of knowledge in society. American Economic Review, v. 35, n. 4, p. 519-530, 1945.

HAMBRICK, D. C. Specialization of environmental scanning activities among upper level executives. Journal of Management Studies, v. 18, $\mathrm{n}$. 3, p. 299-320, 1981.

HAMBRICK, D. C. Environmental scanning and organizational strategy. Strategic Management Journal, v. 3, p. 159-174, 1982.

HERRING, J. P. Tópicos fundamentais de inteligência: processo para identificação e definição de necessidades de inteligência. In: PRESCOTT, John E.; MILLER, Stephen H. Inteligência Competitiva na Prática. Editora Campus, São Paulo, 2002. p.274-291.

KAHANER, L. Competitive intelligence: how to gather, analyze, and use information to move your business to the top. Nova York: Touchstone Books, 1996.

LIEBOWITZ, J. Strategic intelligence: business intelligence, competitive intelligence, and knowledge management. [S.I.]: Auerbach, 2006.

MARGUEL LTDA. Artefatos em Estanho São Judas Tadeu: catálogo de vendas. São João del-Rei, 2012.

MASON, E. S. Price and production policies of large-scale enterprise. American Economic Review, v. 29, p. 64-71, Mar. 1939.

McGONAGLE, J. J.; VELLA, C. M. Competitive intelligence in action. The Information Management Journal, v. 38, n. 2, p. 64-68, March-April 2004.

MILLER, J. P. O milênio da inteligência competitiva. Porto Alegre: Bookman, 2002. 
OLIVEIRA, P. H.; ALMEIDA, P. P., LACERDA, J. M. Práticas de inteligência competitiva no setor varejista de Belo Horizonte: um estudo exploratório. In: CONGRESSO INTERNACIONAL DE ADMINISTRAÇÃO, 20., 2007, Ponta Grossa. Anais... Ponta Grossa: UEPG, 2007. Disponível em: <http://www.admpg.com.br/2007/index.php?page=5\&lang=1\&sub=17>. Acesso em: 16 mar. 2016.

PACHECO-DE-ALMEIDA, G. Erosion, time compression, and selfdisplacement of leaders in hypercompetitive environments. Strategic Management Journal, v. 31, p. 1498-1526, 2010.

PORTER, M. E. Competitive strategy: techniques for analyzing industries and competitors. New York: Free Press, 1980.

PORTER, M. E. The contributions of industrial organization to strategic management, Academy of Management Review, v. 6, n. 4, p. 609-620, Apr. 1981.

PRAHALAD, C. K.; HAMEL, G. The core competence of the corporation. Harvard Business Review, p. 3-15, May/June 1990. Disponível em: <http://www.profrandes.com.br/wp-content/uploads/2013/03/Core-

Competence-of-the-Corporation.pdf>. Acesso em: 16 mar. 2016.

PRESCOTT, J. E. The evolution of competitive intelligence: design a process for action. APMP, Spring 1999.

PRESCOTT, J. E.; MILLER, S. H. Inteligência competitiva na prática. São Paulo: Campus, 2002.

QIU, T. Scanning for competitive intelligence: a managerial perspective. European Journal of Marketing, v. 42, n. 7/8, p. 814-835, 2008.

RODRIGUES, A. F. S. Mineração de metais não-ferrosos. In: RODRIGUES, A. F. S.; FERRAZ, C. P. (Org.). Economia mineral do Brasil. Brasília-DF: Cidade Gráfica, 2009, v. 1, p. 236-257.

SCHUMPETER, J. A. The theory of economic development. Cambridge: Harvard University Press, 1934.

STRATEGIC AND COMPETITIVE INTELLIGENCE PROFESSIONALS - SCIP. [Site oficia/]. Disponível em: <http://www.abraic.org.br>. Acesso em: 20 mar. 12.

SIRMON, D. et al. The dynamic interplay of capability strengths and weaknesses: investigating the bases of temporary competitive advantage. Strategic Management Journal, v. 31, p. 1386-1409, 2010.

STIGLER, G. J. The organization of industry. Chicago: University of Chicago Press, 1983.

TARAPANOFF, K. Inteligência organizacional e competitiva. Brasília: Unb, 2001.

TIROLE, J. The theory of industrial organization. London: The MIT Press, 1988. 
TYSON, K. W.M. The complete guide to competitive intelligence. Lisle (Chicago): Kirk Tyson International, 1998.

WEST, C. Competitive intelligence. New York: Palgrave 